\title{
Development and economic trends in cancer therapeutic drugs: a 5-year update 2010-2014
}

\author{
P Savage ${ }^{*, 1}$ and S Mahmoud ${ }^{2}$ \\ ${ }^{1}$ Department of Medical Oncology, BCCA Vancouver Island, Victoria, BC V8R 6V5, Canada and ${ }^{2}$ Cancer Services, Imperial College \\ Healthcare NHS Trust, London W6 8RF, UK
}

Background: Over the past 20 years, the mechanisms of action, duration of benefits and economic costs of newly licenced cancer drugs have changed significantly; however, summary data on these characteristics are limited.

Methods: In this study, using historical copies of the British National Formulary and relevant contemporary publications, we have documented for each new cancer drug the year of introduction, therapeutic classification, initial indication, median duration of treatment and the cost of treatment at introduction relative to the then current UK GDP per capita.

Results: Before 2000, there were 69 cancer treatment drugs available, of which 50 (72.5\%) were classical cytotoxic drugs. In the subsequent 15 years, there have been 63 more new cancer treatment drugs added, including 20 kinase inhibitors and 11 monoclonal antibodies. The average median duration of treatment with a new drug has risen from 181 days in 1995-1999 to 263 days in 2010-2014. The average cost of treatment has also risen from $£ 3036.91$ (20.6\% of UK per capita GDP) in 1995-1999 to $£ 20233$ (89.0\%) in 2005-2009 and now to £35383 (141.7\%) in 2010-2014.

Conclusions: The last 5 years has seen 33 new cancer drugs. These drugs deliver significant benefits in patient outcomes and are taken for increasing lengths of time. Alongside these clinical benefits, the direct costs of new treatments have increased significantly over the past decade.

Over the past 20 years, the systemic treatment of malignancies has altered from being based almost entirely on the use of classical DNA-damaging cytotoxic chemotherapy drugs to a situation where currently the large majority of new cancer treatment drugs have completely different mechanisms of action (Patel et al, 2014).

The arrival of these new therapeutic drugs has led to important improvements in patient care with increasing response rates, longer durations of benefit and enhanced overall survival, all generally achieved with favourable side-effect profiles (Coiffier et al, 2002; Richardson et al, 2005; Motzer et al, 2009).

Alongside these important developments in clinical care, there has also been an increasing debate regarding the rising costs of the new cancer treatments and how they can be met. This debate on the delivery and funding of optimal modern care to patients in both insurance-based systems and state-funded models is ongoing and featuring more in the political and clinical arenas (Meropol et al, 2009, Sullivan et al, 2011; Experts in Chronic Myeloid Leukemia, 2013; de Souza et al, 2014; Khera 2014).

At present, there is relatively little structured information on how the nature of new cancer treatment has changed, the increasing overall benefits from new treatments and the detailed economic issues relating to provision of care. Previously, in 2010, we published a paper that examined all of the drugs available for the treatment of solid tumours in UK practice from 1955 to 2009, looking at the years of introduction and the relative costs of a standard course of therapy (Savage, 2012). The study documented the rising numbers of new drugs, the changes in the types of drugs arriving and demonstrated the rising costs of treatment. Other 
additional studies have also looked at the similar costs in other countries with similar findings (Kantarjian et al, 2013; Light and Kantarjian, 2013).

In the 5 years since 2009, there have now been a total of 33 further new cancer therapy drugs introduced and as a result the management of many malignancies has significantly changed and outcomes improved. Alongside this progress, there has also been an increasing debate within the clinical world and government on how these increasing costs of modern cancer care are to be addressed (Sullivan et al, 2011, Fojo et al, 2014).

In this 5-year update paper, we have aimed to provide extended information on the numbers of new drugs introduced, their therapeutic classes, the first licenced indication, the median duration of treatment and the relative costs of treatment measured against the contemporary UK GDP per capita at the time of introduction. The data on the timing of a drugs initial sale and the exact costs are taken from the UK market, where the timing of first drug sales and economic data is readily available. However, it is likely that the overall results regarding the drugs characteristics and the economic costs will be similar across most of the major developed countries. The information in this update may be helpful in reviewing the historical trends in cancer therapeutic developments and comparing changing economic issues in cancer care delivery over time.

\section{METHODS}

Drugs. The drugs included in the study are the therapeutic agents where the first indication at the time of their introduction was for the treatment of solid tumours or haematological malignancies. Supportive drugs such as anti-emetics, growth factors and drugs that are used in cancer treatment but previously available for nonmalignant indications, such as corticosteroids, bisphosphonates and denusomab, are not included. In addition, the radioactive agents, including Ibritumomab tiuxetan and Strontium-89, and the two photodynamic therapy agents, Temporfin and Porfimer, are not considered within the scope of this article in view of the specialized facilities needed for their administration.

The classification of the drugs into their therapeutic groups is modelled on that in the British National Formulary (BNF) with minor modification.

The year of the initial sale of the drugs was obtained from review of historical copies of the BNF, which has been published since 1949 with regular six monthly updates introduced from 1981 onwards. The information on the initial selling price of the various drugs was obtained from the BNF, which has contained detailed information on UK retail drug prices since 1987. For the drugs introduced before this, the accurate information relating to the initial selling price was difficult to obtain retrospectively and as a result these have not been included in the economic analysis.

Doses. The doses employed are set using a body surface area of $1.75 \mathrm{~m}^{2}$ or weight of $75 \mathrm{~kg}$ as appropriate. An exception was made for Clofarabine and Mifamurtide, both drugs where the major indication is in paediatric oncology. For these a body surface area of $1.33 \mathrm{~m}^{2}$ was used, which corresponds to that of the median age (13 years) of the patients treated. This study did not take into account any potential dose reductions or treatment delays that may have occurred during the course of treatment.

Duration of administration. The data on the median duration of administration of each new drug are generally taken from the data published reporting the pivotal trials leading to the drugs licensing. In a few cases, data on the median duration of administration were not available and the data on progression-free survival or time to treatment failure were taken as a surrogate measure of the median duration of administration.
Of note, the dose and schedule used in this study relate to the original indication and protocol that was in use at the time of initial introduction. The updated and more modern treatment schedules and in the case of some drugs the most frequent indication may now be significantly different.

Economic analysis. The assessment of the relative drug costs is based on both the nominal cost per day averaged during the cycle of treatment and the overall cost of the therapy based on the median duration of administration. The daily treatment dose and cost were calculated by dividing the total dose per cycle by the number of days in that cycle. Alternatively, for drugs used in continuous daily administration, the standard daily dose is used.

For the calculations of the total dose and cost of the average course of treatment of a new drug, the data on the median length of administration were used to compute the total dose of drugs therapy required during this representative course of therapy. For simplicity, in cyclical therapies, the total dose administered was based on the notional daily dose multiplied by the median number of days on treatment rather than being strict multiples of complete cycles.

For the economic assessments, no consideration was taken for vial/pack size associated with delivering each individual cycle of therapy. The total dose or number of tablets for each drug for the entire course of treatment was calculated as a single figure and a simple arithmetic cost calculated based on the cost of the multiples and fractions of the most economic drug pack size available.

In the case of new drugs initially used as part of a combination therapy, only the cost of the new agent within the combination is assessed. No drug administration, supporting medical therapies, pharmacy or nursing support costs are included in the economic analysis.

For the economic comparators, the annual value of the GDP per capita in the United Kingdom was used (Office of National Statistics, 2014). The actual cost of the drug per day and for the median duration course of treatment is shown as a percentage of the daily or annual UK GDP per capita in the year of the drug's introduction.

\section{RESULTS}

The full data set is shown in Supplementary Information.

The data on the first appearance of cancer treatment drugs in the BNF are shown in Figure 1. The trend in the numbers of new drugs in the 5-year periods indicates that since the first cancer

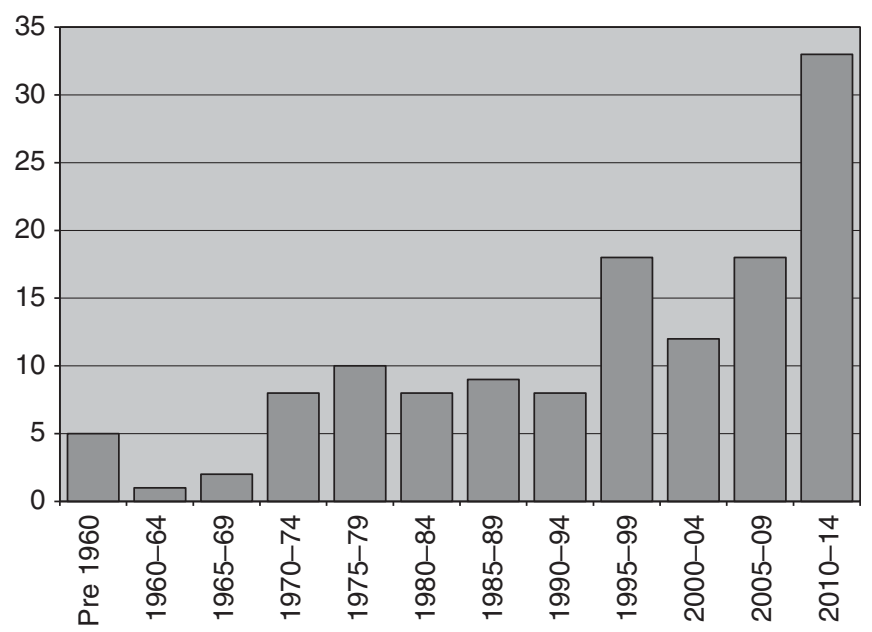

Figure 1. Numbers of new cancer treatment drugs introduced to UK practice from pre-1960 to 2014 viewed in 5-year periods. 
treatment drugs were introduced in the 1950s, there have been a total of 132 cancer therapy drugs introduced. Overall, this gives an average of 11 drugs per 5-year period, however, it is clear that the pace of successful drug development and licencing has increased significantly over the past 20 years with values of $18,12,18$ and most recently 33 for the 5-year periods from 1995 to 2014 .

In Table 1, the therapeutic classifications of the new cancer drugs initially listed in each of the 5-year periods is demonstrated. As can be seen, classical cytotoxic chemotherapy drugs historically form the largest group with a total of 64 agents. However, it is now clearly apparent that the rate of arrival of new classical cytotoxic drugs has slowed dramatically with only 10 agents launched in the past 10 years. In contrast, the most frequent type of new cancer drug is now the kinase inhibitors with 19 new agents in the past 10 years, whereas monoclonal antibodies are now the third most frequent class of new drug with 8 new agents since 2005 .

In Table 2, the initial therapeutic indication of the new cancer drugs introduced since 1990 is demonstrated. Overall, of the 89 new drugs subsequently introduced, the highest total number are for breast cancer (13), colorectal cancer (10) and prostate cancer (9). In contrast over the past 10 years, the highest number of new drugs for any single indication is now for renal cancer (6), a diagnosis that had only one new drug introduced in the preceding 15 years.

In Table 3, the median durations of treatment for the new drugs introduced in each of the 5-year periods from 1995 to 1999 onwards are demonstrated. These data are taken from the key licencing studies or for the older drugs a relevant contemporary

Table 1. Classification of the cancer treatment drugs introduced in each 5-year period from 1985 onwards

\begin{tabular}{|c|c|c|c|c|c|c|c|c|}
\hline & Pre 1985 & 1985-1989 & 1990-1994 & 1995-1999 & 2000-2004 & 2005-2009 & 2010-2014 & Total \\
\hline Classical cytotoxic & 31 & 4 & 4 & 11 & 4 & 4 & 6 & 64 \\
\hline Hormonal agents & 3 & - & 2 & 4 & 2 & - & 3 & 14 \\
\hline Cytokines & - & 1 & 1 & - & - & - & - & 2 \\
\hline Peptides & - & 3 & 1 & 2 & - & 1 & 1 & 8 \\
\hline Monoclonal antibody & - & - & - & 1 & 3 & 2 & 6 & 12 \\
\hline Kinase inhibitor & - & - & - & - & 1 & 6 & 13 & 20 \\
\hline mTor inhibitor & - & - & - & & & 1 & 1 & 2 \\
\hline $\begin{array}{l}\text { Proteosome inhibitor } \\
\text { Thalidomide analogue }\end{array}$ & - & - & - & - & 1 & 2 & 1 & 4 \\
\hline Others & - & 1 & - & - & 1 & 2 & 2 & 6 \\
\hline Total & 34 & 9 & 8 & 18 & 12 & 18 & 33 & 132 \\
\hline
\end{tabular}

Table 2. The initial tumour site indication of new cancer treatment drugs introduced since 1990

\begin{tabular}{|c|c|c|c|c|c|c|}
\hline Indication & 1990-1994 & 1995-1999 & 2000-2004 & 2005-2009 & 2010-2014 & Total \\
\hline Adrenal & - & - & - & 1 & - & 1 \\
\hline Ascites & - & - & - & - & 1 & 1 \\
\hline $\mathrm{BCC}$ & - & - & - & - & 1 & 1 \\
\hline Bladder & - & - & - & - & 1 & 1 \\
\hline Breast & 1 & 5 & 3 & 1 & 3 & 13 \\
\hline Carcinoid & - & 1 & - & - & 1 & 2 \\
\hline CLL & - & 1 & 1 & - & - & 2 \\
\hline $\mathrm{CML}$ & - & - & 1 & 2 & 2 & 5 \\
\hline CNS & - & 1 & - & - & - & 1 \\
\hline Colorectal & - & 2 & 4 & 2 & 2 & 10 \\
\hline Haem other & - & - & - & 1 & 1 & 2 \\
\hline Leukaemia & 3 & 1 & - & 2 & 1 & 7 \\
\hline Lung & - & - & 1 & 1 & 3 & 5 \\
\hline Melanoma & - & - & - & - & 3 & 3 \\
\hline Myeloma & - & - & 1 & 2 & 1 & 4 \\
\hline Lymphoma & - & 1 & 1 & 1 & 4 & 7 \\
\hline Ovary & 1 & 3 & - & - & & 4 \\
\hline Pancreas & - & 1 & - & - & & 1 \\
\hline Prostate & 2 & 2 & - & 1 & 4 & 9 \\
\hline Renal & 1 & - & - & 3 & 3 & 7 \\
\hline Sarcoma & - & - & - & 1 & 1 & 2 \\
\hline Thyroid & - & - & - & - & 1 & 1 \\
\hline Total & 8 & 18 & 12 & 18 & 33 & 89 \\
\hline
\end{tabular}


study. As can be seen in Table 3, the average of the median durations of administration for the new drugs licenced in each period has increased significantly from 181 days in 1995-1999 to 263 days in 2010-2014.

This increase is more clearly shown in the second column that shows the mean data from these periods with the multiple clinically highly similar GnRH drugs removed. The data with the multiple GnRH agents removed show the average median duration of administration to have risen from 118 days in 1995-1999, to 181 in 2000-2004, to 211 in 2005-2009 and now to 263 in 2010-2014.

The absolute historical costs and the relative costs compared with the contemporary GDP per capita for both per day during treatment and for the median duration of treatment are shown in Table 4. This demonstrates the median cost of treatment has risen with each of the 5 -year periods since 1995 . The daily cost while on treatment has risen from $£ 33.25$ (82.6\%) in 1995-1999 to £160.34 (235.1\%) in 2010-2014. In the second column, the average cost of the median duration of therapy shows a similar but more rapid rate of increase rising from $£ 3037$ (20.6\%) in 1995-1999 to $£ 20233$ (89.0\%) in 2005-2009 and continuing the rise to $£ 35383$ (141.7\%) for 2010-2014. The faster rate of rise of the average total costs of therapy is a product of the increasing median duration of therapy, which has increased from 118 days to 263 days during this period as shown in Table 3.

\section{DISCUSSION}

Over the past 20 years, the systemic therapy of cancer has been an area of great scientific and clinical research and patient care and outcomes have improved significantly (Patel et al, 2014). A measure of this progress can be seen in the increasing numbers of new therapeutic drugs that have been introduced over the period as shown in Table 1. Of the total of 132 cancer therapeutic drugs, which have been listed in the BNF, 33 (25\%) of them have been introduced in the past 5 years and 51 (39\%) in the past 10 years.

In addition to this significant increase in the numbers of new drugs, the therapeutic classification of the newly arriving agents has also changed dramatically during this period. Before 2000, there were a total of 69 cancer treatment drugs of which $50(72.5 \%)$ were classical cytotoxic agents. In the past 15 years, the total number of drugs has now increased to 132 but of the 63 new agents only $14(22 \%)$ have been classical cytotoxics, whereas $20(32 \%)$ are kinase inhibitors and $12(19 \%)$ are monoclonal antibodies. It is likely that this shift from classical cytotoxic drugs to new targeted agents will further increase as already seen in the 2010-2014 figures, as there appears to be relatively little therapeutic gain from these cytotoxics compared with existing therapies. In contrast, the impact of therapies that target tumours via alternate and novel pathways has been dramatic with TKI therapies revolutionising the treatment of CML and renal cancer and the addition of monoclonal antibodies to standard chemotherapy significantly

Table 3. Average of the median duration of administration for the new cancer drugs introduced from 1995 to 2014 shown in 5-year periods

\begin{tabular}{|l|c|c|}
\hline & $\begin{array}{c}\text { Average median } \\
\text { duration of administration } \\
\text { (all new drugs) }\end{array}$ & $\begin{array}{c}\text { Average median } \\
\text { duration of administration } \\
\text { (new drugs excluding } \\
\text { GnRH) }\end{array}$ \\
\hline $1995-1999$ & 181 days & 118 days \\
\hline $2000-2004$ & 181 days & 181 days \\
\hline $2005-2009$ & 260 days & 211 days \\
\hline $2010-2014$ & 263 days & 263 days \\
\hline Abbreviation: $\mathrm{GnRH}=$ gonadotropin-releasing hormone. \\
\hline
\end{tabular}

improving cure rates in non-Hodgkin's lymphoma and in the adjuvant treatment of breast cancer.

The data on the initial indication for the new drugs are shown in Table 3 with a summary of the tumour types for the drugs introduced since 1990. Historically, the tumour types that have the largest numbers of drugs are the common malignancies of breast cancer (13), colorectal cancer (10) and prostate cancer (9) reflecting the scale of research for these common malignancies and the large number of patients eligible for treatment. In contrast over the past 10 years, the majority of drugs have been initially licensed for generally rarer conditions, including renal cancer (6) lymphoma (5) and CML (4), which is a reflection of the targeted nature of these drugs and the success of modern science in exploiting these pathways.

The overall median duration of therapy with new cancer drugs has increased with each 5-year period rising from 118 days in 1995-1999 to now 263 days for the new drugs introduced in 20102014. Although it is to be expected that new drugs are better and work for longer than older drugs, this rising figure also has two associated factors. The first is that the majority of new cancer drugs treatments are now no longer taken for a prescribed standard number of cycles, as was generally the case for classical cytotoxics. The majority of the new drugs are now taken continuously until progression. The other important factor is that many of the new drugs are not replacing earlier therapies but are now being taken sequentially after previously established therapies to give multiple lines of therapy. The situation in kidney cancer shows this as a good example, where 10 years ago there was only minimal benefit from interferon, the only drug available for most patients, the treatment course for current patients with metastatic disease could now be Sunitinib or Pazopanib first line, followed by Axatinib and then by Everolimus. Similarly, for patients with CML can now have first-line treatment with Imatinib and the further effective TKI therapy with Dasatinib. In both cases, these sequential treatments are supported by NICE and usually routinely NHS funded.

The increase in the number of cancer patients and the recent rapid expansions in the range, number and costs of their drug treatments are causing stress to government, insurers and patient's health costs worldwide.

The data in Table 4 give updated information on the average costs of modern cancer treatment first licenced since 1995. Although the actual cost to the NHS may for some drugs be reduced by confidential discounting schemes, it is apparent from the recommended price data that the cost per day during treatment has risen significantly, in both direct cost and relative to the contemporary UK GDP per capita. The average cost per day on treatment has risen from $£ 33.25(82.6 \%)$ in $1995-1999$ to now $£ 160.34$ (235.1\%) in 2010-2014. In parallel, the average figures for the cost of the median duration course of treatment are significantly impacted by the rising duration of administration

Table 4. Economic analyses of cancer new drugs introduced from 1995 to 2014

\begin{tabular}{|l|c|c|}
\hline & $\begin{array}{c}\text { Average cost per day } \\
\text { on treatment (\% of } \\
\text { daily GDP per capita) }\end{array}$ & $\begin{array}{c}\text { Average cost per median } \\
\text { duration of treatment } \\
\text { (\% of annual GDP per } \\
\text { capita) }\end{array}$ \\
\hline $1995-1999$ & $£ 33.25(82.6 \%)$ & $£ 3037(20.6 \%)$ \\
\hline $2000-2004$ & $£ 49.66(97.3 \%)$ & $£ 7973(43.4 \%)$ \\
\hline $2005-2009$ & $£ 143.70(233.4 \%)$ & $£ 20233(89.0 \%)$ \\
\hline $2010-2014$ & $£ 160.34(235.1 \%)$ & $£ 3533(141.7 \%)$ \\
\hline $\begin{array}{l}\text { Abbreviation: GDP = gross domestic product. The average of the median cost of treatment } \\
\text { with the new agents introduced in each 5-year period is shown as the contemporary actual } \\
\text { cost figure and as a percentage of the UK GDP per capita in the first year of listing in the } \\
\text { British National Formulary. }\end{array}$ \\
\hline
\end{tabular}


that has more than doubled during this period. As a result, the costs of the total course of treatment has risen even more significantly with an approximately seven-fold increase compared with per capita GDP from $£ 3037$ (20.6\%) in 1995-1999 to now $£ 35383$ (141.7\%) in 2010-2014.

The management of cancer patients has been changing significantly over the past two decades and this pace is reflected clearly in the record number of new cancer drugs arriving in the past 5 years with a total of 33 new agents. The scale of oncology research and the great advances made in the understanding of the processes occurring in tumour cells and how they can be targeted makes it likely that similar or greater numbers of new drugs will arrive over the next 5-10 years. As can be seen the shift from cancer being treated with fixed courses of classical cytotoxics to prolonged therapy with new agents is already being reflected in the change in the classification of the new drugs now favouring kinase inhibitors and monoclonal antibodies and this success is reflected in the rising average length of administration and clinical benefit.

This dramatic increase in the nature and the benefits from the new treatments has been associated with significantly rising costs, which alongside the direct pharmacy costs also contains significant increases in costs for medical supervision, imaging and costs related to the management of toxicity and side effects (Niraula et al, 2014) It is apparent the financial costs in delivering these advances in care are becoming increasingly challenging worldwide.

It is hoped the data in this paper may of interest to those interested in the history and development of cancer treatment and may also help support the debate on future funding for cancer treatment.

\section{REFERENCES}

Coiffier B, Lepage E, Briere J, Herbrecht R, Tilly H, Bouabdallah R, Morel P, Van Den Neste E, Salles G, Gaulard P, Reyes F, Lederlin P, Gisselbrecht C (2002) CHOP chemotherapy plus rituximab compared with CHOP alone in elderly patients with diffuse large-B-cell lymphoma. N Engl J Med 346: 235-242.

Experts in Chronic Myeloid Leukemia (2013) The price of drugs for chronic myeloid leukemia (CML) is a reflection of the unsustainable prices of cancer drugs: from the perspective of a large group of CML experts. Blood 121: 4439-4442.

Fojo T, Mailankody S, Lo A (2014) Unintended consequences of expensive cancer therapeutics-the pursuit of marginal indications and a me-too mentality that stifles innovation and creativity: the John Conley lecture. JAMA Otolaryngol Head Neck Surg 140: 1225-1236.

Kantarjian HM, Fojo T, Mathisen M, Zwelling LA (2013) Cancer drugs in the United States: Justum Pretium-the just price. J Clin Oncol 31: 3600-3604.
Khera N (2014) Reporting and Grading Financial Toxicity. J Clin Oncol 29: 3337-3338.

Light DW, Kantarjian H (2013) Market spiral pricing of cancer drugs. Cancer 119: 3900-3902.

Meropol NJ, Schrag D, Smith TJ, Mulvey TM, Langdon Jr RM, Blum D, Ubel PA, Schnipper LE,. American Society of Clinical Oncology (2009) American Society of Clinical Oncology guidance statement: the cost of cancer care. J Clin Oncol 27: 3868-3874.

Motzer RJ, Hutson TE, Tomczak P, Michaelson MD, Bukowski RM, Oudard S, Negrier S, Szczylik C, Pili R, Bjarnason GA, Garcia-del-Muro X, Sosman JA, Solska E, Wilding G, Thompson JA, Kim ST, Chen I, Huang X, Figlin RA (2009) Overall survival and updated results for sunitinib compared with interferon Alfa in patients with metastatic renal cell carcinoma. J Clin Oncol 27: 3584-3590.

Niraula S, Amir E, Vera-Badillo F, Seruga B, Ocana A, Tannock IF (2014) Risk of incremental toxicities and associated costs of new anticancer drugs: a meta-analysis. J Clin Oncol 32: 3634-3642.

Office of National Statistics (2014) Accessed via http://www.theguardian.com/ news/datablog/2009/nov/25/gdp-uk-1948-growth-economy\#data.

Patel JD, Krilov L, Adams S, Aghajanian C, Basch E, Brose MS, Carroll WL, de Lima M, Gilbert MR, Kris MG, Marshall JL, Masters GA, O’Day SJ, Polite B, Schwartz GK, Sharma S, Thompson I, Vogelzang NJ, Roth BJ (2014) Clinical Cancer Advances 2013: Annual Report on Progress Against Cancer from the American Society of Clinical Oncology. J Clin Oncol 32: 129-160.

Richardson PG, Sonneveld P, Schuster MW, Irwin D, Stadtmauer EA, Facon T, Harousseau JL, Ben-Yehuda D, Lonial S, Goldschmidt H, Reece D, San-Miguel JF, Bladé J, Boccadoro M, Cavenagh J, Dalton WS, Boral AL, Esseltine DL, Porter JB, Schenkein D, Anderson KC (2005) Assessment of Proteasome Inhibition for Extending Remissions (APEX) Investigators. Bortezomib or high-dose dexamethasone for relapsed multiple myeloma. N Engl J Med 352: 2487-2498.

Savage P (2012) Development and economic trends in cancer therapeutic drugs in the UK from 1955 to 2009. J Oncol Pharm Pract 18: 52-56.

de Souza JA, Yap BJ, Hlubocky FJ, Wroblewski K, Ratain MJ, Cella D, Daugherty CK (2014) The development of a financial toxicity patientreported outcome in cancer: The COST measure. Cancer 120: 3245-3253.

Sullivan R, Peppercorn J, Sikora K, Zalcberg J, Meropol NJ, Amir E, Khayat D, Boyle P, Autier P, Tannock IF, Fojo T, Siderov J, Williamson S, Camporesi S, McVie JG, Purushotham AD, Naredi P, Eggermont A, Brennan MF, Steinberg ML, De Ridder M, McCloskey SA, Verellen D, Roberts T, Storme G, Hicks RJ, Ell PJ, Hirsch BR, Carbone DP, Schulman KA, Catchpole P, Taylor D, Geissler J, Brinker NG, Meltzer D, Kerr D, Aapro M (2011) Delivering affordable cancer care in high-income countries. Lancet Oncol 12: 933-980.

This work is published under the standard license to publish agreement. After 12 months the work will become freely available and the license terms will switch to a Creative Commons AttributionNonCommercial-Share Alike 4.0 Unported License.

Supplementary Information accompanies this paper on British Journal of Cancer website (http://www.nature.com/bjc) 